\title{
Jole
}

\section{LEADERSHIP STUDIES IN THE CROSS ROADS}

\section{Abstract}

This paper describes a collaborative curriculum project integrating 4 leadership programs at three academic levels. What emerged from this effort was a theoretical model understood as a boundary object that allows our diverse perspectives a space within which we can communicate, collaborate, and learn from each other.

\section{Problématique}

Universities and their academic programs are entangled in multiple cultural and political worlds and must account for themselves to multiple stakeholders. While all academic programs must respond to this call to accountability - interdisciplinary/transdisciplinary programs are especially challenged due to their complexity and multiple agendas (Hyun, 2011, Klein, 1996). A useful schema drawn from the Nuffield Foundation (Klein, 1996, pp. 10-11) for beginning the process of making sense of inter/transdisciplinary work is found in describing efforts as either bridging across and between traditional disciplines or reconstructing disciplines to reflect new conditions. Also suggested is a third option of transdisciplinary integration. Transdisciplinarity suggests a higher order synthesis and integration of ideas and topics into a unified form able to satisfy both the practical and theoretical exigencies of the practice or project at hand as well as address the breakdown in traditional categories of logic and reason (Nicolescu, 2008). This paper is about the creation of one such form arising from the practice of teaching leadership studies and is presented as a "boundary object" (Bowker \& Star, 1999, pp. 15-16; Star \& Griesemer, 1989, p. 393) capable of meeting the needs of the variety of stakeholders interested in our programs. Program curricula, assessment rubrics and frameworks interpreted as boundary objects may help mitigate the confusion, uncertainty, and difficulty in negotiating multiple perspectives. As will be discussed below boundary objects can be understood as arising at the intersection of experience and knowledge creating naturalized practices that become more or less iconic. Star and Griesemer (1989) maintain that,

Boundary objects are objects which are both plastic enough to adapt to local needs and constraints of the several parties employing them, yet robust enough to maintain a common identity across sites. They are weakly structured in common use, and become strongly structured in individual-site use. They may be abstract or concrete. They have different meanings in different social worlds but their structure is common enough to more than one 
world to make them recognizable, a means of translation. The creation and management of boundary objects is key in developing and maintaining coherence across intersecting social worlds. (p. 393)

In contrast to the above, I argue that prescriptive models for program development, evaluation, and assessment are insufficient given the complexity, heterogeneity, and emergent nature of the practice. Instead, what are called for are conceptual models that adequately capture and integrate historical traces of dynamic program activity in readiness for an unfolding future without foreclosing their continual dynamic emergence. This processual view of reality (Rescher, 1996) is central to the project of leadership studies as conceived here.

The model described below originated from a series of lengthy meetings among representatives of one undergraduate, two masters, and one doctoral program in leadership studies at a small Jesuit university. Key drivers of these meetings to discuss program coherence were issues of relationality, diversity, social justice, knowledge, experience, and purpose. These issues continually asserted themselves in faculty meetings, curriculum development efforts, and larger school and university forums. Likewise, outcome measures, accountability, and performance issues were factors involved in our meetings. Both internally (e.g., content, curriculum design, \& pedagogy) and externally (e.g., political environments, outcome measures) these pressures were understood by this group as a function of the complexity and interrelations of leadership studies subject matter, social-historical factors, and the psychology and behavior of individuals and groups. The intention of this group at the beginning of the process was not to create a boundary object or even a systematic model of what we were doing. The initial impetus was to make sense of our shared practice in an effort to find common meanings around what we all meant by leadership and leadership studies. Faculty members involved in the project have presented the model outline at conferences and to groups within our own university community. These experiences have resulted in my attempt in this paper to further articulate the sense of our efforts. However, and notwithstanding my use of the pronoun we below, this model and its argued utility is not meant to imply or assert that what is discussed here reflects the thinking or pedagogical perspective of faculty and staff of our school in whole or in part.

Our conversations began with the general questions: What is leadership studies? And, what are we doing to advance that interpretation? Leadership as loosely and generally interpreted here involves the complexity of social transaction(s) involving purpose, influence, relationship, and power. Leadership studies, from this perspective, is about how these phenomena are active in leaders, followers, and participants in personal, familial, social, organizational, and political contexts. However, some consider leadership to be an "empty signifier" (Ford, Harding, \& Learmouth, 2008 , p. 10) and critically question its ubiquitous and popular employment as an explanatory construct for social behavior. In contrast to this perspective Goethals \& Sorenson (2007), for example, have done work attempting to forge a general theory of leadership.

Certainly, these questions would seem strange to scholars in established academic disciplines. How could we credibly ask how we were advancing (or teaching) material from a field we hadn't previously adequately defined or understood? Our answer to this question, and the one I will work from in this paper, is that the nature of our focal interest (leadership) is an emergent phenomenon that shifts and transforms dynamically from situation to situation and context to context. This response is further elaborated by noting that this dynamic transformation from situation to situation also characterizes the self as it continuously navigates and negotiates its own intrinsic and extrinsic meanings. 
I am speaking of the self in three distinct ways. First, I note the third person perspective that implies a self that observes the emergent properties of other situations and persons. Secondly, that people are also themselves both other and observer and in that process dynamically come to terms in relationship with each other and the objects of their shared intentions and purposes from a second person perspective. Finally, each of us is an existent (Cavarero, 2014) or an ontological and phenomenological self that carries first person sensations, feelings, and thoughts that are apparently separate from others but always entangled in a self/other relationship intrasubjectively. As will be developed below these three divisions in the perspectives of the complex self are introduced as part of this model used to describe curriculum theorizing.

\section{Experience \& Knowledge}

The complex self is implicated in the relationship between experience and knowledge. My making this distinction is drawn in part from Dewey's Experience and Nature (1958) and while he used the term nature to characterize what I am calling knowledge I think the distinction holds. He was contrasting experience with nature as it is revealed by science and reflective thought. I maintain, along with Mead (1938) that reflective consciousness is synonymous with reflective thought, the scientific method, and the perception and experience of objects as other to the observer. Also, both Dewey and Mead argued that the difference between experience and nature was a conceptual distinction and not an ontological separation (Dewey \& Bentley, 1949, p. 324). I follow them in that regard as well - particularly in the analysis of the self above.

According to Shotter (2011) how we are phenomenally and existentially (our experience) is continually subsuming what we know and hold as true, certain, and stable (our knowledge). This is also taken up by Taylor (2002) where he notes that "Experience is that wherein our previous sense of reality is undone, refuted, and shows itself as needing to be reconstituted" (pp. 281-282). However, to the extent that our habits of mind keep us unconsciously entrained to historical patterns we don't learn anything new and, consequently, experience very little. Here we can understand habits to encompass ways of knowing or seeing the world - ways of physically, emotionally and mentally being in the world that are built on knowledge. To the extent we do learn something new we necessarily disrupt or transform the status quo (Piaget, 1971; Vygotsky, 1978), or in Taylor's words: "reality is undone".

This distinction lays the groundwork for the claim that experience is disrupted by the apparent unity of knowledge (by encouraging habitual response) and that knowledge is disrupted by the apparent diversity of experience (characterized by emergence and transformation). This problem becomes acute when working with a conceptual model (as offered here) that is meant to make sense of the contents, contexts, and processes underlying the transdisciplinary practice of teaching and learning in leadership studies.

So, to one degree or another, what we do as scholars, teachers, staff, and administrators (and, I would argue, any organizational actor) continually undermines the stabilities that have resulted from what we have done historically and built our history from. We continue to upset and perturb the specific courses, program design, and intentions that are historically present. The difficulty of accommodating this situation is explicitly recognized as I articulate the distinction between knowledge and experience as mediated by method. However, this formulation itself is problematic. Because language subsumes all our efforts at articulating any ostensive definition of experience as non-conceptual or non-linguistic the very category itself (experience), is anomalous. The device of definition separates. Nonetheless, given limitations of space and time it is necessary to bracket this metaphysical problem and recognize that there is, following Dewey (1958), Mead, (1932/2002), Todes, (2001), Wegner (1998), and others - the philosophical and theoretical necessity to hold experience, participation, embodiment, and other characterizations of the immediacy of being 
alive as the source of dynamic change that tends through language, toward dynamic stability.

Both methodologically and practically the model emerging from our faculty conversations reflected our various practices, actions, and behaviors as scholars in this field over the time of our conversations. We came to the table with our experiences as faculty and with our conceptualizations of what and how we teach leadership studies in the hope that we could make sense of the entire school effort working in this transdisciplinary field.

A related core issue is that the leadership studies programs at our university are loosely coupled to national and international efforts at teaching leadership and leadership studies. We have found that our programs with their humanistic, Jesuit, and eclectic focus don't easily fit with more traditionally minded programs that do teach from a core body of knowledge considered central to leadership studies. In general (and in my view) there are two broad, mostly U.S. perspectives, in leadership studies and an emerging perspective of a mostly European based critical leadership studies (Chandler \& Kirsch, 2018; Collinson, 2017; Ford, Harding, \& Learmonth, 2008). In the first U.S. perspective there is a central focus on both popular and foundational texts on leadership which reveal an effort to construct a discipline of leadership (Goethals \& Sorenson, 2007; Harvey \& Reggio, 2011). In the second U.S. camp there is recognition that the roots of leadership studies are found in the disciplines of ethics, political science, history, social psychology, etc., (Harter, 2006). It is my view that adherents of this latter perspective tend to utilize and bridge conceptual frameworks from these more established fields to interpret leadership phenomena, usually positional leadership, to complement organizational and management studies. Critical leadership studies tends to reflect postmodern and poststructural interpretations and problematizes core assumptions of the U.S. interpretation (Collinson, 2017). Neither of the dominant U.S. perspectives, in my view, embrace the emergent and complex nature of leadership as a transdisciplinary practice. Goethals \& Sorenson
(2007) engage in a comprehensive discussion of these differences and similarities. Critical leadership studies makes room for these interpretations however, and will serves as part of the context for the theorizing outlined here.

Our curriculum is widely divergent both within the scope of our four programs and in comparison to curricula at other universities. What all four programs do have in common, however, is a commitment to Ignatian pedagogy and its explicit recognition of the role of reflection in transformational learning. The Jesuit and Ignatian outline for an appropriate pedagogy is as follows: Context > Experience $>$ Reflection $>$ Action $>$ Evaluation $>$ Context > Experience >etc. (Jesuit Net, 2011). This connected cycle captures both biological and phenomenological (context and experience) and rational and abstract (action and evaluation) components of consciousness as mediated by reflection. As such the Ignatian model necessarily includes personal, communal, and ethical elements of being.

This paper will proceed in three broad movements. First, I will briefly discuss emerging patterns in transdisciplinary discourse. Second, I will describe the theoretical model that emerged from our effort to answer our questions about our programs. Finally, I will analyze and interpret the model through a combination of the discourses latent in the model itself. This analysis is meant to do two things. First, to clarify and elaborate the soundness of the model, and second, to extend the discussion into a more specific and contextualized framing of a theory of practice and a theory of knowledge as they relate to transdisciplinary scholarship in leadership studies.

\section{Emerging Patterns}

As noted above our efforts at program sensemaking grew out of the realization that issues in leadership studies were increasingly associated with relationality, diversity, social justice, knowledge, experience, and purpose. We realized that working across multiple disciplines complicated our integration work and 
we sought to better understand this. Coming to understand interdisciplinary, multidisciplinary, cross disciplinary, and transdisciplinary definitions and projects (Dodig-Crnkovic, et al., 2017; Eigenbrode, et al., 2007) helped us in addressing this complexity. Key thinkers in the field (Klein, 2010; 2008; 2004; 1998; Klein \& Newell, 2002; Nicolescu, 2002; 2008) approach the general problem of integration of knowledge and practice from both pragmatic and theoretical perspectives. Klein's (1998) focus on social epistemology is consistent with the general context of this paper and indicates a warrant for experiments in transdisciplinary thinking. Klein (1998) noted, "Advancing the proposed project [transdisciplinarity] will require developing a common conceptual framework, vocabulary, and pedagogies" (p. 2). And of course, this is problematic in that making something common out of something inherently diverse or uncommon (the problem of holism) subverts the very complexity and diversity initially celebrated in the transdisciplinary project (Klein, 1996, pp. 13-14). Nicolescu (2002) approaches this issue directly and suggests that paradox is at the heart of a transdisciplinary methodology. This insight goes to the distinction between knowledge and experience pointed out above: making our worlds common is a function of knowledge; our production of novelty, diversity, and change is consistent with experience. Working with this tension is, I believe, at the heart of leadership studies.

In approaching this dilemma, the assumptions implicit in the common-sense notion of creating "a common conceptual framework" should be critically analyzed (Field \& Lee, 1992). Normally a conceptual framework is thought to anticipate or structure a priori the content or problem the framework is meant to make sense of (Anfara \& Mertz, 2006, pp. xiv) or explain. This paper is about a framework to be used both after the phenomena in question has been investigated, enacted, or developed and from within the experience of the individuals emerging from that interaction. Also necessary is a move from seeing an object of knowledge as a reference we orient toward or need to learn about in our seeking after our goal
(Scardamalia \& Bereiter, 2006) to a boundary object from which we depart, or work from as the local, immediate, and dynamic elements of living emerge in our experience. In seeing knowledge as an aspect of emerging context rather than an ensemble of content I argue that our practice of teaching leadership studies is at the core of what and how we define what leadership studies is (see Raelin, 2016). The boundary object (conceptual framework) resulting from this project is meant to help make sense of emergent transdisciplinary phenomena after it has emerged or been enacted by faculty and students not a template or schema by which to prospectively design, plan, enact, predict, or measure performance prior to its enactment. Interpreting integrated curriculum development as a boundary object can help navigate the paradox of unity in diversity that challenges experience and the paradox of diversity in unity that challenges knowledge.

\section{Content + Context + Process}

To engage in this unity/diversity tension our group developed a conceptual framework integrating each of our departments' fundamental theory and curriculum constructs and mission statements into a loose and mutually informing opportunity for dialogue. We made three critical distinctions with regard to the overall framework. First, we articulated our paradigmatic knowledge and content assumptions as to their ontological (what a thing is), epistemological (how we know things), and axiological (how we value things) foundations. Next, we discussed the contexts and methodological choices within which our programs operate and in which we interpret leadership studies operating in. Finally, we discussed the processes by which we experience, learn, teach and practice leadership studies. Each of these three domains can be elaborated in terms of undergraduate, master's level, and $\mathrm{PhD}$ levels of training; suggesting distinct and autonomous frames of reference held together by the larger school and university mission. 


\section{Knowledge as Content}

The knowledge as content dimension is meant to capture the broad movement that has historically structured western thought as investigations into being (ontology or metaphysics), knowing (epistemology), and valuing (axiology) (Wilbur, 1998). Our content domain is an effort to ensure that in our work we adequately incorporate the sense and content of these categories. Each of the following content categories is briefly described and then evoked through a description of what the ideal in terms of praxis might be. The language below reflects a focus on the individual but recognizes all actions arise out of the reciprocal influence relationship with others and is always social. Also, implicit in these content categories are the vagaries of experience. The interpenetrating and dialectical nature of the knowledge/experience distinction is obvious here where we see experience insert itself into the knowledge domain. This is consistent with Barad's (2007, pp. 37, 185) call for the integration of the ontological, epistemological, and axiological into one coherent construct. Nonetheless I feel it useful to make the distinction to achieve a pragmatic and operational clarity. It is to that end that each dimension is articulated as something that someone does. Each abstract element of the knowledge domain is activated through experience and continually mediated through language.

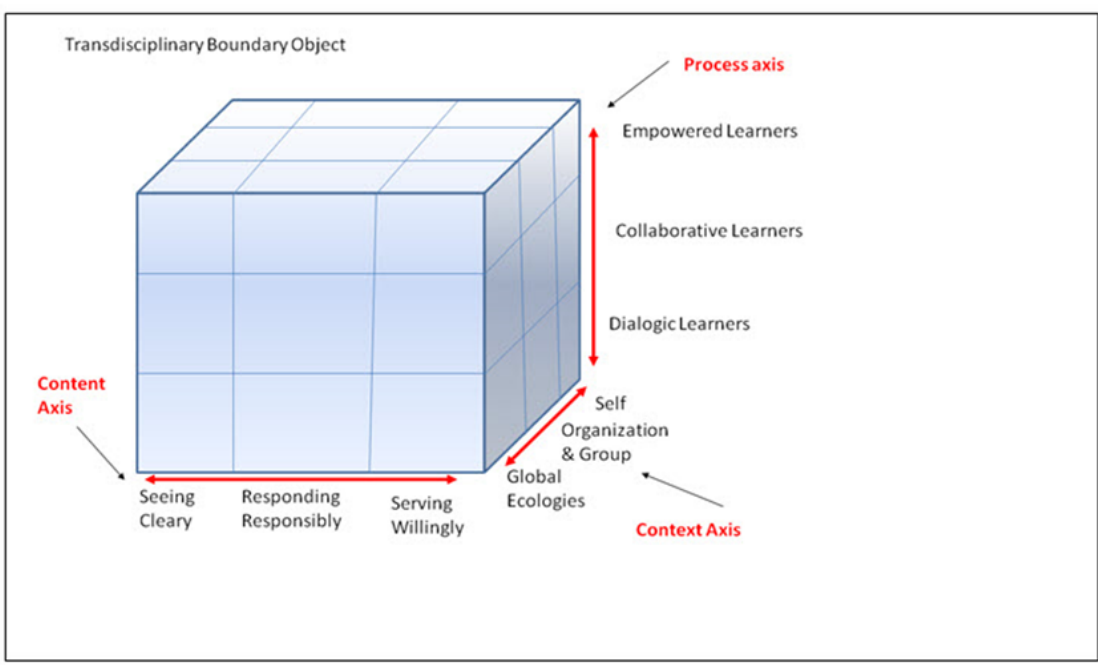

Figure 1. Transdisciplinary Boundary Object

\section{Seeing the Objects of Knowledge Clearly - Ontological Perspectives}

A persistent critique of modernism is that essentialist notions of truth can be had through the method of objective science. While we understand this critique, we are also committed to keeping a primary connection to the realist paradigm (Maxwell, 2012). Certainly, one of the most powerful of content categories is the description of the world that natural science has created. Leadership studies is traditionally rooted in these scientific discourses (see for example, Burns, 1982; Harvey \& Riggio, 2011; Heifetz, 1994; Stogdill \& Bass, 1981) that reveal the subtlety and depth of the objectified natural and social world(s). We make a commitment to see these phenomena clearly and to use as the basis of our study the imperative that our 
seeing of the world, in all its manifestations, is done through as un-obscured a lens as possible. The basis for much of the postmodern revolution has, after all, come from the undoing or unobscuring of common sense notions of empirical science through, for example, physics and philosophy. What we have learned to see has revealed itself as only a partial story. Seeing as broadly interpreted here is the result of knowledge built out of a particular historical and cultural experience - this refers to the dominance of logos, signification, and objectivity mostly rendered through the visual context (see Cavarero, 2005) and tends - through experience - to become habitual. Our curriculum and our programs, while committed to developing the skills to see are also committed to developing the skills to unsee. Habitual conditioning of ordinary historical consciousness creates assumptions, frames, scripts, maps, or mental models that can occlude clear seeing through a process of default perceptions (Johnson-Laird, 1983; Schank \& Abelson 1977; Siegel, 1999, 2007; Varela, Thompson, \& Rosch 1991). Ordinary consciousness is understood as the habitual "everyday coping" (Stewart, 1995, pp. 110-111) of everyday experience as contrasted to the reflective consciousness associated with thinking about thinking, critical reflection, and scientific reasoning. To the extent that ordinary consciousness and common sense pervade the scientific world view then it too becomes a denizen of Husserl's natural attitude (Sokolowski, 2000) and so obscures the facts of experience.

Our processes, pedagogies, methods and content are meant to mitigate this conditioning and work towards a reflective and clear view of what we experience. While we recognize the power and efficacy of the objective, visual, and third person perspectives we also realize they are a partial view of phenomena and must be understood in the wider context of human experience and sensory capacities. Inevitably we are forced in our efforts at understanding the phenomena of the content domain to include both cultural and bio-physical aspects of our knowing. Of course, this draws us back to experience. Nonetheless, the perspectives taken in this first major area of knowing are critical.

Language as Social and the Inevitability of Response - Epistemological Perspectives

What our clear seeing may teach us, however, is that we see out of reflective consciousness and that reflective consciousness is problematic, complex, and deeply connected to human language, speech, and meaning. As such we realize that how we know is as important as what we know. Language is understood here as the vehicle for both consciousness and thought (seen broadly as an epistemological issue) and is the fulcrum on which both ontology and axiology turn. Here we follow the stream in social science that interprets identity and meaning as a social phenomenon - as occurring always in relation to an other. A primary assumption about human beings is that we are social beings and are immersed in a continuous round of relational interactions. These interactions happen both between individuals and within individuals in a manner described by Mead (1934) as involving continuous gesture/response cycles. Each gesture I make is interpreted by an other as a response. Each response is also a gesture. This continual conversation of gestures is understood by Mead (1934; 1938) and others (e.g., Blumer, 1969; Francovich, 2017; Valsiner \& van der Veer, 2000) as the foundation of human society and sociality. Our inevitable practice of response requires a normative interpretation to stabilize interactions over time. Communication becomes an inevitable domain of study as we continuously negotiate our multiple perspectives. Understanding and dealing with conflict and difference as a result of divergent perspectives is central to our curriculum. Consequently, we make a commitment to ethical action as an imperative given the complex, interdependent, and relatively fragile state of our physical and social world.

Ethics out of Action and Service to Others - Axiological Perspectives

The third category in the content domain is related to the question of value. From our perspective, the determination of value is a function of what we do - of our activity, our practice, of both our 
habitual and normal behaviors and our spontaneous and creative behaviors. Obviously, this area of inquiry is fundamentally lodged within the ambit of experience. Our leadership programs embrace a commitment to service and teach and model an ethic of willing service to and for others. However, this is notwithstanding the justified critique of women and other marginalized groups that have been negatively affected historically and currently by the tropes of service, and help as covers for the exploitation and use of people as a means to an end. This willing service we feel is the ultimate reason and justification for action assuming the social nature of being human. It is also our assumption that habit developed from the experience of coming back to our context and our direct experience (i.e., a habit of reflection, see Schön, 1987) inevitably creates the need for a life devoted to service for and with others. What we are able to do in including the axiological dimension in our content domain is look at this knowledge and value emerging from action more or less objectively and compare and contrast claims consistent with Jesuit and humanistic values to ideas and theories that would argue against a service-for and with-others ethic.

\section{Method as Context}

One of the enduring methodological problems for leadership studies (and I submit for studying anything) is the unit of analysis problem. That is, where do we begin and end our investigation of phenomena? Where do we definitively say - this is not that? We take the position that the world of phenomena is complex and that understanding what our senses and our minds tell us is always problematic. This results in a fundamental ambivalence about making claims that definitively explain or describe leadership, persons, groups, or societies. Our understanding is informed by Dewey \& Bentley (1949) as noted above - when they suggest that what we typically take for an ontological separation (e.g. person and environment or self and other) is actually a conceptual distinction. This implies that our perspective is implicated in the rendering of the thing perceived. Which is to say that it is dependent on a host of factors typically not taken into consideration when common sense thought says, that person is not that table. Dewey and Bentley argue that

Distinctions which are indispensable
to form and use in efficient conduct of
inquiry... are converted into something
ontological, that is to say, into something
taken to exist on its own account prior
to inquiry and to which inquiry must
conform. (p. 324)

Suggested here is a distinction (not a separation) between three dimensions of phenomena that correspond to the individual, group, and collective level of human sociality. We see these distinctions or levels as describing the context of human inquiry into leadership studies from diverse methodological perspectives. These distinctions also each suggest an affinity with areas within the content domain discussed above. Our curricula are designed to make sense of the context domain through study of relevant content that reflect the wholeness of human beliefs, knowledge, and values. We also recognize, following Dewey \& Bentley above, that our assumptions regarding the prior and enduring substantial nature of assumed ontologically separate categories are problematic. This discussion is, of course, quite problematic philosophically. Realism, anti-realism and a host of other competing perspectives demand interpretation and consideration. My perspective is one of a critical realism that serves to integrate both materialist and constructionist perspectives (see Bhaskar, Danermark, \& Price, 2018).

Personal level. This dimension of the context domain is focused on the subjective, individual, psychological, phenomenological, and/or spiritual aspects of leadership, leading, following, and participating in culture. At this level, we focus on our own lived experience of being present to one another. We investigate our own stories, histories, and personal narratives, and the objective views of rational and naturalist thinking on the nature of the individual person - including the brain, mind, and body as a whole. We apply the rubrics of the content dimensions to our inquiry into the personal and 
subjective aspects of how reciprocal influence works within, between, and among molar selves. While the ontology of the self is contested by postmodern theorizing (Benhabib, 1992; Giddens, 1998; Holstein \& Gubrium, 2000) the emerging consensus on the narrative self (Bruner, 1990; Boje, 2001; Cavarero, 2014; Sparrowe, 2005; Verhesschen, 2003) situates the personal dimension as both the source and the object of social processes. Also, operant at this level is the idea that as persons we can be more or less habitual in what we do - or more or less spontaneous. The questions of creativity, novelty, and innovation become central to any discussion uniquely aimed at the personal dimension. I believe that inquiry into the personal dimension allows a depth and focus to our work as teachers, scholars, and practitioners that would otherwise be compromised. Curriculum and methods associated with the personal dimension (as well as the other dimensions discussed below) are interpolated with readings and dialogue emerging from the content domain in a natural process of program integration. Specific texts for specific courses are compared to the relevant domains and dimensions in a retrospective analysis of program goals and objectives.

Communal level. This dimension of leadership studies takes explicit account of the reciprocal nature of human relating with others to create and inhabit dyads, families, communities, and organizations. We see this as a meso-level category that links both the personal and generalized global dimensions of our larger analytic framework. Primary to our thinking at the communal level are questions of language and communication, culture, and the creation of boundaries, norms, and habitual patterns of relating (Bateson, 1979; Berger \& Luckmann, 1966; Dewey \& Bentley, 1949; Lakoff, 1987; Vygotsky, 1986; 1978). Of increasing importance in this domain are the issues of power, power relations, and the ways in which individuals adapt to or are coerced by the larger frameworks and contexts they inhabit (Freire, 2000; Foucault, 1982; Stacey, 2012; 2003). Also important is a thorough discussion and understanding of language and its role in the creation of both identity and social cohesion. Key notions of symbol, narrative, and artifact (Mead, 1932; Stewart, 1996; Vygotsky, 1989; Wertsch, 1998) bind together the individual with the increased scale of the collective. The influence of culture on the individual and the influence of the individual on culture become key themes.

This dimension opens to (among others) literature in anthropology, cultural studies, organizational science, bureaucracy, markets, and the beginnings of social policy discussions (Argyris, 1999; Schein, 2004; Weber, 1958). The leadership implications in communal and organizational life are investigated from both pre-modern, modern, and postmodern perspectives (Hatch, 2006; Shafritz, Ott, \& Jang, 2005; Shirky, 2008; Wenger, 1998). This analysis is tied to the personal dimension as well as rendered through the rubrics of the content domain of our overarching theoretical framework.

Generalized level. Finally, we reach the greatest scope of our thinking as we consider the behavior and effect of large groups and collectives making up our global perspective. Here we see a transition to what I understand as statistical abstract thinking, that is, thinking that is based on descriptions arising from data aggregation and inference and generalization about things both unseen and un-experienced at either the personal or organizational levels but clearly present in its effects on our lives. Scholarship here is rendered through the lenses of sociology, policy studies, quantitative analyses, history, political science, economics, and the full sweep of academic disciplines devoted to understanding the whole (Bauman, 2007; Brand, 2009; Eitzen, \& Baca Zinn, 2006; Meadows, 2008; Stone, 2002). It is the integration of these perspectives into a coherent discussion of leadership that our programs aim their attention. We also see the localization of global phenomena through increased travel, social tools, and international education programs (Steger \& Wahlrab, 2017). This return in the realm of context of the global to the personal is a key theme in courses throughout our programs and is reflected in the diversity of students and faculty as we pursue the discourse in leadership studies. 


\section{Experience as Process}

Our emerging views on the experience-as-process dimension encompass the increasing interest in human inquiry into the dynamic, complex, and emergent nature of the world and our experience of it (Byrne \& Callaghan, 2014; Dewey, 1958; Emirbayer, 1997; Gadamer, 1975; Rescher, 1996). The critique of essentialist dogmas and ideologies leveled by postmodernists have at their base the understanding that the nature of the world is more consistent with change and flux than with enduring verities based on anthropocentric and hegemonic cultural interpretations. A consequence of this focus is a move away from paternalistic and infantilizing relationships. People that know are recast as people in the process of knowing and as such as fallible, confused, and/or vulnerable as the most basic learner. Consequently, this domain affects our sense of pedagogy and the effort to understand the phenomenology inherent in our ongoing participation with each other, with students, and with our larger community. A theory of the living present that frames the temporal nature of our experience into a non-linear view of time helps make sense of the process of being together (Mead, 1932; Stacey, 2003). What emerged out of our conversations was both a clarity around how we generally see the praxis of leadership studies as well as a clear set of distinctions guiding program pedagogies. While each program level suggested a guiding pedagogical focus what we all realized is the each of the so-called levels transcends and includes all previous ways of knowing the self and the world.

Agency, Empowerment \& Freedom - Empowered Learners. Certainly, one of the most significant issues in leadership studies is the question of influence in terms of agency. Key questions arising from this are how and why some people have influence and power over others? How do I make my way in the world having relatively more or less power or influence over or through others? What do I need and require for being a free agent in the world? What implication does my agency have on others? Power and the use of power are central questions dealt with throughout our programs' curricula (see above). We discovered that the interpersonal and intrapersonal experiences of students in the undergraduate leadership program were particularly focused on issues related to these themes. Faculty in the undergraduate leadership program are concerned that students can articulate and defend their own meanings in the context of other students articulating and defending different meanings. The undergraduate is encouraged to find his or her voice (Cavarero, 2005) - the students know they have something to offer society that is valuable and important. Social justice, equity, and ecological and economic sustainability emerge as themes for the leadership studies curriculum.

Sociality, Collaboration, and Community Collaborative Learners. Growing out of a community nurtured on empowerment and freedom we find ourselves in larger and larger networks that demand from each of us the skills of adaptability, patience, and openness to others. Basic skills in communication, negotiation, mediation, and compromise are necessary in pluralistic environments. Students in our programs are explicitly oriented toward these habits of mind. Relational sensitivity and emotional intelligence are understood to underlie all social intercourse. In the specific context of Master's level graduate leadership education, collaboration describes the desired identification and relationship with a community of scholars. The graduate student in leadership studies enters their program of study with a clear sense of the efficacy of their own voice, and leaves with commitment to the value of understanding different voices in the conversation and the skills to both create new meaning in a social context as well as adapt to others' meanings.

Understanding, Dialogue, and Transformation Dialogic Learners. The foregoing all suggest that relationship and communication are key to the transdisciplinary project of leadership studies. We recognize that serious engagement with the other as we continually re-create each other is key to our learning about leadership. In order to do this, we have to approach the hermeneutic process of understanding directly. This requires an engagement with both the theory and the practice of dialogue 
and the meeting of horizons of, in Gadamer's (1976, p. 9) words, our inevitable and ongoing prejudice of how the world of knowledge really is. As noted above the nature of this is is problematic. It is a necessary is that is always changing as we bring our experience into the light of reflective consciousness and, with others, create the ongoingness of our social worlds. We have found that at the doctoral level this dimension is fundamental and critical. It is a necessary perspective built on the previous perspectives that allows for students and candidates to develop ability to progressively experience the world prior to naming it - to interact with a strange other first in direct experience and only after that experience to judge or evaluate. The starting point is empowerment, a key marker on the journey is collaboration, but the destination of leadership studies under this framework is dialogue.

\section{Enlightened Duality}

As our group began to sum up our efforts at making sense of our practices I noticed a kind of closure happening around the model. The embodied experience of dialogue emerged at one end of the continuum as a response to the abstract knowledge or content domain at the other end. I began to understand these concepts as bookends to the philosophical problem of realism vs. idealism or the methodological problem of positivism vs. interpretivism. I have also begun to see practice, experience, and reflection on experience as vital and necessary for teaching or learning leadership studies. Certainly, schools and universities everywhere talk about and/or promise lifelong learning, transformation, and a fundamental integration of knowledge; this is also what is being looked for in program reviews, outcomes assessment, and other evaluation methods. And of course, all of us have difficulty in doing exactly this.

What we have developed is an object that can generate a coherent conversation around these issues conversations that focus on the phenomenological experience of being in situations and having to come to terms with the paradox of duality - of sameness and difference. We can't teach these lessons abstractly or through didactic instruction. We must participate. Shotter (2009) observes:

... the difficulties we encounter here are not difficulties that we can formulate as problems which can be solved by the application of rational thought; they are not intellectual difficulties. They are difficulties of a very different kind. They are orientational or relational difficulties, difficulties to do with our embodied expectations in relation to the things and events we encounter within them, difficulties of a kind that can only be overcome by relating ourselves to our surrounding differently. (p. 222)

The explicit inclusion of experience into our programs that becomes systematically related to the knowledge we both expect from our students and participate with as scholars is a step toward that different relational orientation that Shotter speaks of. I noticed that the various orientations of students and faculty to the programs and curricula were often reflections of quite disparate styles in learning, communicating, or expressing needs. By privileging the experiential in the curriculum, we could see how the diversity of our community was being accommodated and how knowledge built from these roots was likewise variegated and perspectival. For me the framework really did begin to do the work of a boundary object in that it accommodated the variation in content, methodological focus, and pedagogy that exists not only between the levels of credentialing but also between the differences exhibited by individual faculty and students.

\section{Conclusion}

The emergent purpose of our efforts at structuring the experience and outcomes of our four programs was to provide reference points, guidelines, and language for describing what we do. What we do is meant to give shape to the theory and practice of 
leadership. Leadership, as mentioned above, is an elusive concept and, we feel, best worked with as an emergent of experience in the context of knowledge. As noted above this is a complex and difficult body of ideas to give shape and definition to. It appears to require a healthy combination of philosophy, social theory, psychology, ethics, scientific naturalism, and multiple other disciplines. In a word: everything. And of course, as others have noted one can't really have a theory of everything. The scope is too vast the epistemological problems seemingly intractable. Nonetheless, we persist in trying to make sense. This model reflects one effort at making sense of our practice.

This body of work also has the potential to be a boundary object for staff, administration, and external stakeholders as we continue to navigate the complexity of offering an interdisciplinary/ transdisciplinary academic program of leadership studies. This conceptual artifact is defined at the intersection of knowledge and experience and reflective of a nondual emergent process. Built into this framework is the imperative that each of us take responsibility for our actions and for the consciousness that emerges from our actions. It is in this primary call that leadership studies might prove more than a theoretical and retrospective accounting of the behavior of humans in the social and natural world. 


\section{References}

Anfara, V. A., \& Mertz, N. T. (2006). Theoretical frameworks in qualitative research. London: SAGE.

Argyris, C. (1999). On organizational learning. Malden. Massachusetts: Blackwell Business.

Barad, K. M. (2007). Meeting the universe halfway: Quantum physics and the entanglement of matter and meaning. Durham: Duke University Press.

Berger, P. L., \& Luckmann, T. (1966). The social construction of reality; a treatise in the sociology of knowledge. Garden City, N.Y: Doubleday.

Bhaskar, R., Danermark, B., \& Price, L. (2018). Interdisciplinarity and wellbeing: A critical realist general theory of interdisciplinarity. London: Routledge Ltd.

Blumer, H. (1969). Symbolic interactionism: Perspective and method. Berkeley, CA: University of California Press.

Brand, S. (2009). Whole Earth Discipline: An Ecopragmatist Manifesto. Viking Penguin. NY

Brenner, J.E., (2008). The logic of transdisciplinarity. in Nicolescu, B. (2008). Transdisciplinarity: Theory and practice. (pp. 155-163). Cresskill, NJ: Hampton Press.

Bauman, Z. (2007). Liquid times: Living in an age of uncertainty. Cambridge: Polity Press.

Bruner, J. (1990). Acts of meaning. Cambridge, MA: Harvard University Press.

Benhabib, S. (1992). Situating the self: Gender, community, and postmodernism in contemporary ethics. New York: Routledge.

Boje, D. M. (2001). Narrative methods for organizational and communication research. London; Thousand Oaks, CA: Sage Publishers.

Bowker, G. C., \& Star, S. L. (1999). Sorting things out: Classification and its consequences. Cambridge, MA: The MIT Press.

Bruner, J. (1990). Acts of meaning. Cambridge, MA: Harvard University Press.

Byrne, D., \& Callaghan, G. (2014). Complexity theory and the social sciences. London: Routledge.

Cavarero, A. (2014). Relating narratives: Storytelling and selfhood. Routledge.

Cavarero, A. (2005). For more than one voice: Toward a philosophy of vocal expression. Stanford University Press.

Chandler, J. L. S., \& Kirsch, R. E. (2018). Critical leadership theory. Basingstoke, Hampshire: Palgrave Macmillan.

Collinson, D. (2017). Critical leadership studies. Leadership, 13(3), 272-284.

Crotty, M. (1998). The foundations of social research: Meaning and perspective in the research process. London; Thousand Oaks, CA: Sage Publications. 


\section{References}

Dewey, J. (1958). Experience and nature. New York: Dover Publications Inc.

Dewey, J., \& Bentley, A. F. (1949). Knowing and the known. Boston: Beacon.

Dodig-Crnkovic, Kade, Wallmyr, Holstein, and Almer. (2017) Transdisciplinarity as seen through information, communication, computations, (Inter-) Action and Cognition. In (forthcoming) Information Studies and the Quest for Transdisciplinarity. Burgin, M. and Hofkirchner, W. (Eds). World Scientific Publishing

Eigenbrode, S.D., Bosque-Pérez, N. A., O'Rourke, M., Wulfhorst, J. D., Althoff, D. M., Goldberg, C. S., Merrill, K., et al. (2007). Employing philosophical dialogue in collaborative science. Bioscience, 57(1), 55-64.

Eitzen, D. S., \& Baca Zinn, M. (Eds.). (2006 2nd Edition). Globalization: The Transformation of Social Worlds. Belmont, CA:Thompson-Wadsworth

Emirbayer, M. (1997). Manifesto for a relational sociology. American Journal of Sociology, 103(2), 281-317; 281.

Field, M., \& Lee, R. (1992). Assessment of interdisciplinary programmes. European Journal of Education, 27(3), pp. 277-283.

Ford, J., Harding, N., \& Learmonth, M. (2008). Leadership as identity: Constructions and deconstructions. Basingstoke: Palgrave Macmillan.

Foucault, M. (1982). The subject and power. Critical Inquiry, 8(4), 777-795.

Francovich, C. (2017). A Meadian Approach to Radical Bohmian Dialogue. Journal for the Theory of Social Behaviour, 47: 98-128.

Freire, P. (2000). Pedagogy of the oppressed (30th anniversary ed.). New York: Continuum.

Gadamer, H. (1975). Truth and method. New York: Seabury Press.

Gadamer, H. (1976). Philosophical Hermeneutics. Berkeley CA: University of California Press.

Giddens, A. (1991). Modernity and self-identity. Stanford, CA: Stanford University Press.

Goethals, G. R., \& Sorenson, G. J. (2007). The quest for a general theory of leadership. Cheltenham, UK; Northampton, MA: Edward Elgar.

Harter, N. (2006). Clearing in the forest: On the study of leadership. West Lafayette, Indiana: Purdue University Press.

Harvey, M., \& Riggio, R. E. (2011). Leadership studies: The dialogue of disciplines. Cheltenham: Edward Elgar Pub.

Holstein, J. A., \& Gubrium, J. F. (2000). The self we live by: Narrative identity in a postmodern world. New York: Oxford University Press.

Hyun, E, (2011) Transdisciplinary higher education curriculum: a complicated cultural artifact. Research in Higher Education Journal. 11, 1-19. 


\section{References}

Jesuit Net (2011). Accessed on 10/10/11 at http://www.ajcunet.edu/Jesuit-Education-and-Ignatian-Pedagogy

Johnson-Laird, P. N. (1983). Mental models: Towards a cognitive science of language, inference, and consciousness. Cambridge, Mass: Harvard University Press.

Klein, J.T. (1998). Notes Toward a Social Epistemology of Transdisciplinarity. Communication au Premier Congrès Mondial de la Transdisciplinarité (Convento da Arrábida, Portugal, 2-6 Novembre 1998. Accessed from http://basarab.nicolescu.perso.sfr.fr/ciret/bulletin/b12/b12c2.htm September 3, 2011.

Klein, J.T. (1996). Crossing Boundaries: Knowledge. Disciplinarities, and Interdisciplinarities, Charlottesville: University Press of Virginia

Klein, J.T. (2008). Evaluation of Interdisciplinary and Transdisciplinary Research: A Literature Review." American Journal of Preventive Medicine, 35(2S): S116-23.

Klein, J.T., \& Newell, W., (2002) Strategies for Using Interdisciplinary Resources. Issues in Integrative Studies, 20: $139-60$.

Klein, J. T. (2004). Prospects for transdisciplinarity. Future, 36, 515-526.

Meadows, D.H. (2008). Thinking in Systems: A Primer. White River, VT: Chelsea Green Publishing.

Lakoff, G. (1987). Women, fires and dangerous things: What categories reveal about the mind. Chicago: University of Chicago Press.

Maxwell, J. A. (2012). A realist approach for qualitative research. Los Angeles: SAGE.

Mead, G. H. (1932/2002). The philosophy of the present. Amherst, N.Y: Prometheus Books.

Mead, G. H. (1934). Mind, self, and society: From the standpoint of a social behaviorist. Chicago: University of Chicago Press.

Mead, G. H., (1938). The philosophy of the act. Chicago: Ill., The University of Chicago press.

Nicolescu, B. (2008). Transdisciplinarity: Theory and practice. Cresskill, NJ: Hampton Press.

Nicolescu, B. (2002). Manifesto of Transdisciplinarity. Albany, NY: SUNY Press.

Piaget, J. (1971). Biology and knowledge. Chicago: University of Chicago Press.

Raelin, J. A. (2016). Leadership-as-practice: Theory and application. New York: Routledge.

Rescher, N. (1996). Process metaphysics: An introduction to process philosophy. Albany: State University of New York Press.

Scardamalia, M., \& Bereiter, (2006) Knowledge Building. in Sawyer, R. K. (Ed). The Cambridge handbook of the learning sciences. (pp. 97-115). Cambridge: Cambridge Univ. Press.

Schank, R \& Abelson R. (1977), Scripts, Plans, Goals and Understanding, Hillsdale, NJ: Erlbaum

Schein, E. (2004). Organizational culture and leadership (3rd ed.). San Francisco: Jossey-Bass. 


\section{References}

Schön, D. A. (1987). Educating the reflective practitioner: Toward a new design for teaching and learning in the professions (1st ed.). San Francisco: Jossey-Bass.

Shotter, J. (2011). Embodiment, abduction, and expressive movement: a new realm of inquiry? Theory \& Psychology, 21(4), 439-456.

Shotter, J. (2009). Bateson, double description, Todes, and embodiment: Preparing activities and their relation to abduction. Journal for the Theory of Social Behaviour, 39(2), 219-245.

Sokolowski, R. (2000). Introduction to phenomenology. Cambridge, UK ; New York: Cambridge University Press.

Sparrowe, R. T. (2005). Authentic leadership and the narrative self. Leadership Quarterly, 16(3), 419-439.

Stacey, R. D. (2012). Tools and techniques of leadership and management: Meeting the challenge of complexity. London; New York: Routledge.

Stacey, R. D. (2003). Complexity and group processes: A radically social understanding of individuals. Hove; New York: Brunner-Routledge.

Star, S.L., Griesemer, J., (1989). Institutional Ecology, 'Translations' and Boundary Objects: Amateurs and Professionals in Berkeley's Museum of Vertebrate Zoology, 1907-39". Social Studies of Science 19 (3): 387-420.

Steger, M. B., \& Wahlrab, A. (2017). What is Global Studies?: Theory \& Practice. Routledge.

Stewart, J. R. (1996). Beyond the symbol model: Reflections on the representational nature of language. Albany: State University of New York Press.

Stogdill, R. M., \& Bass, B. M. (1981). Stogdill's handbook of leadership: A survey of theory and research (Rev. and expanded ed. / Bernard M. Bass ed.). New York: Free Press.

Stone, D. (2002). Policy paradox: The art of political decision making (Revised Edition ed.). New York: W. W. Norton \& Company.

Taylor, C. (2002). Understanding the other: A Gadamerian view on conceptual schemes. in Malpas, J. E., von Arnswald, U., \& Kertscher, J. (Eds), Gadamer's century: Essays in honor of Hans-Georg Gadamer (pp. 279297). Cambridge (Mass.): the MIT press.

Todes, S. (2001). Body and world. Cambridge, Mass: MIT Press.

Valsiner, J., \& van der Veer, R. (2000). The social mind: Construction of the idea. Cambridge, U.K.; New York: Cambridge University Press.

Varela, F. J., Thompson, E., \& Rosch, E. (1991). The embodied mind: Cognitive science and human experience. Cambridge, MA: MIT Press.

Verhesschen, P. (2003). 'The poem's invitation': Ricoeur's concept of mimesis and its consequences for narrative educational research. Journal of Philosophy of Education, 37(3), 449-465. 


\section{References}

Vygotsky, L. (1986). Thought and language. Cambridge, MA: MIT Press.

Vygotsky, L. S. (1978). Mind in society. Cambridge, MA: Harvard University Press.

Weber, M. (1958). The protestant ethic and the spirit of capitalism. New York: Scribner.

Wenger, E. (1999). Communities of practice; Learning, meaning, and identity. Cambridge: Cambridge University Press.

Wertsch, J. V. (1998). Mind as action. New York: Oxford University Press

Wilbur, K. (1998). The marriage of sense and soul. New York: Random House. 